\title{
The impact of the Polish mass breast cancer screening program on prognosis in the Pomeranian Province
}

Piotr Woźniacki ${ }^{1}$, Jarosław Skokowski ${ }^{1}$, Krzystof Bartoszek², Anna Kosowska ${ }^{1}$, Leszek Kalinowski ${ }^{3}$, Janusz Jaśkiewicz ${ }^{1}$

\begin{abstract}
${ }^{1}$ Department of Oncological Surgery, Medical University of Gdansk, Gdansk, Poland ${ }^{2}$ Department of Mathematics, Uppsala University, Uppsala, Sweden ${ }^{3}$ Department of Medical Laboratory Diagnostics and Bank of Frozen Tissues and Genetic Specimens, Medical University of Gdansk, Gdansk, Poland
\end{abstract}

Submitted: 23 February 2015

Accepted: 12 September 2015

Arch Med Sci 2017; 13, 2: 441-447

DOI: https://doi.org/10.5114/aoms.2016.60387

Copyright (c) 2016 Termedia \& Banach

\section{Abstract}

Introduction: Mammographic screening results in diagnosis of less advanced breast cancer (BC). A meta-analysis of randomized clinical trials confirmed that BC screening reduces mortality. In 2007, the National Breast Cancer Screening Program (NBCSP) was established in Poland with the crucial aim of reducing mortality from $B C$. The purpose of this study was to assess the impact of participation in the NBCSP on prognosis.

Material and methods: A single institution, non-randomized retrospective study was undertaken. The study population comprised 643 patients with BC treated in the Department of Surgical Oncology (DSO) at the Medical University of Gdansk over a 4-year period, from 01.01.2007 until 31.12.2010. Patients were divided into two groups: group A - patients who participated in the NBCSP $(n=238,37.0 \%)$; and group B - patients who did not participate in the NBCSP $(n=405,63.0 \%)$.

Results: Statistical analysis revealed that group A displayed a less advanced AJCC stage (more patients in AJCC stage I, $p=0.002$ ), lower tumor diameter (more patients with pT1, $p=0.006$, and $\mathrm{pT}<15 \mathrm{~mm}, p=0.008$ ) and a lower incidence of metastases to axillary lymph nodes (more patients with pNO, $p=0.01$ ). From 2009 to 2010 the NBCSP revealed a statistically significant benefit - significantly more patients in stage $0+\mathrm{I}(60.7 \%$ vs. $48.8 \%$, $p=0.018)$ and with tumors $\mathrm{pT}<15 \mathrm{~mm}(48.8 \%$ vs. $35.1 \%, p=0.011)$ were observed in group A.

Conclusions: The study results revealed the beneficial impact of the NBCSP. Superior prognostic factors and favorable staging were observed in women who participated in the NBCSP.

Key words: breast cancer, screening, mass screening, prognostic factors, AJCC staging, prognosis.

\section{Introduction}

Breast cancer $(\mathrm{BC})$ is a major global health problem. $\mathrm{BC}$ is the most common cancer in women worldwide. Despite decreasing mortality, it is still the most frequent cause of death among women suffering from cancer [1]. Early stage diagnosis of neoplasms is a crucial factor responsible for improvements in treatment. Screening mammography is the leading method of early diagnosis of $\mathrm{BC}$ [2]. In a meta-analysis of 8 randomized clinical trials comprising over 600,000 women, Gøtzsche and

\author{
Corresponding author: \\ Piotr Woźniacki MD, PhD \\ Department \\ of Oncological Surgery \\ Medical University of Gdansk \\ 7 Dębinki St \\ 80-952 Gdansk, Poland \\ Phone: +48601457909 \\ E-mail: pwozniacki83@ \\ gmail.com
}


Nielsen evaluated that performing mammography in women in the 50 to 69 age group, over a 2- or 3-year interval, reduced mortality from BC by approximately $10 \%$ to $25 \%$ [3].

When comparing Poland to Nordic and Western European countries or the USA, significantly inferior survival was found. According to EUROCARE-4, 5 -year survival rates in Western European countries are approximately $90 \%$, whereas in Poland the rate is $77.4 \%$ [4]. The major causes of inferior survival are ineffective early diagnostics and poor registration for surgical treatment with advanced $B C$. This result is caused by lack of knowledge of $\mathrm{BC}$ prophylaxis, low participation in screening and an ineffective health system, which causes delays in treatment [5-7].

In January 2007, due to the great success of mass breast cancer screening programs (MBCS) throughout the world, the Polish Health Minister established a Poland-wide, unified National Breast Screening Program (NBCSP - In Polish: Populacyjny Program Wczesnego Wykrywnia Raka). In order to manage the NBCSP, 16 regional centers were established with the program headquarters located at the Maria Sklodowska-Curie Memorial Cancer Center and Institute of Oncology in Warsaw. All of the mammography centers participating in the program were obliged to use the Computerized System of Monitoring Prophylaxis (CSMP), which contains complete personal data, case histories and mammography results for all patients. The program was available to women aged 50 to 69 years without symptoms of BC who, in the last 2 years, had not undertaken a mammogram. The NBCSP operated according to the principles of active screening. The National Health Fund posted

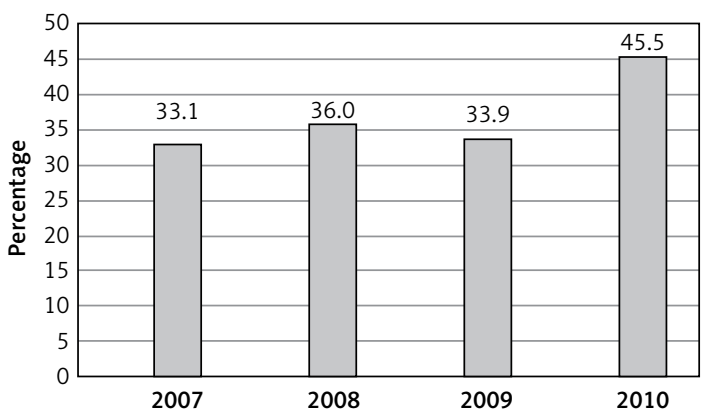

Figure 1. Participation in the NBCP in Pomeranian Region (years 2007-2010) written invitations addressed to eligible patients identified with the CSMP. Every mammography scan was analyzed independently by two radiologists adequately trained according to the NBCSP principles and scored with a quality assurance system - BIRADS (Breast Imaging Reporting and Data System). The fundamental aim of the NBCSP is to reduce mortality from $B C$ to the level obtained in leading European countries.

This present study is an attempt to assess the influence of the NBCSP on AJCC (American Joint Committee on Cancer) staging in patients suffering from $B C$.

\section{Material and methods}

A single-institution, non-randomized, retrospective study was undertaken. The inclusion criteria were: invasive or in situ breast carcinoma and female gender, age from 50 to 69 years. From women eligible to attend the NBCSP in the Pomeranian Region in 2007 over 57500 (33.1\%) women participated in the NBCSP, in 2008 over 62500 (36.0\%), in 2009 over 58800 (33.9\%), and in 2010 over 79000 (45.5\%) (Figure 1). From 01.01.2007 to $31.12 .2010,3650$ women suffering from BC were detected in the Pomeranian region in all age groups, including 1042 (28.7\%) who attended the NBCSP (Table I).

The study population comprised 743 patients with BC treated in the Department of Surgical Oncology (DSO) in the Medical University of Gdansk over a 4-year period, from 01.01.2007 to 31.12.2010. Age ranged from 50 to 69 years; the median was 58.8 years. Clinical and histopathological data (including tumor histology, tumor size and axillary lymph nodes status) were collected from medical history and histopathology databases. All patients were then checked using the CSMP in order to establish whether they participated in the NBCSP.

From 338 patients who participated in the NBCSP, 100 patients were excluded from the study because they reported BC symptoms (palpable mass in breast) in the CSMP questionnaire. Patients were then divided into two groups: group Apatients who participated in the NBCSP $(n=238$, $37.0 \%)$; and group $\mathrm{B}-$ patients who did not participate in the NBCSP $(n=405,63.0 \%)$ (Figure 2).

Table I. Presentation of BC patients detected in Pomeranian Region from 2007 to 2010 divided into participants and non-participants of the NBCSP (N-NBCSP)

\begin{tabular}{|lccccc|}
\hline Variable & 2007 & 2008 & 2009 & 2010 & $\Sigma$ \\
\hline NBCSP & $249(29.9 \%)$ & $190(24.3 \%)$ & $265(27.7 \%)$ & $338(31.7 \%)$ & $1042(28.7 \%)$ \\
\hline N-NBCSP & $582(70.1 \%)$ & $591(75.7 \%)$ & $690(72.3 \%)$ & $725(68.3 \%)$ & $2588(71.3 \%)$ \\
\hline$\Sigma$ & $831(22.8 \%)$ & $781(21.5 \%)$ & $955(26.3 \%)$ & $1063(29.2 \%)$ & 3630 \\
\hline
\end{tabular}




\section{Statistical analysis}

All clinical data and study results were categorized, collected and stored in a computer database in the Microsoft Excel program. For the statistical analysis of data, Statistica (StatSoft, version 10.0) and the R (version 2.15.0) prop. test function with Yates' continuity correction were used. Quantitative data such as frequency of incidence were expressed as a percentage (\%) with one decimal place. The null hypothesis was rejected at a significance level of $p<0.05$. Quantitative variables were studied using the $\chi^{2}$ test for comparing proportions, and ordinal variables were compared using the Mann-Whitney U-test. In order to compare group A with group B we used one-tailed tests with the null hypothesis that group $A$ has the same or lower proportion. There were very few (ca 4.5\%) missing data, and we have no reason to suspect that missingness depends on the unobserved values.

\section{Results}

There were more patients with $\mathrm{BC}$ participating in the NBCSP in AJCC stage I (45.8\% vs. $34.1 \%, p=$

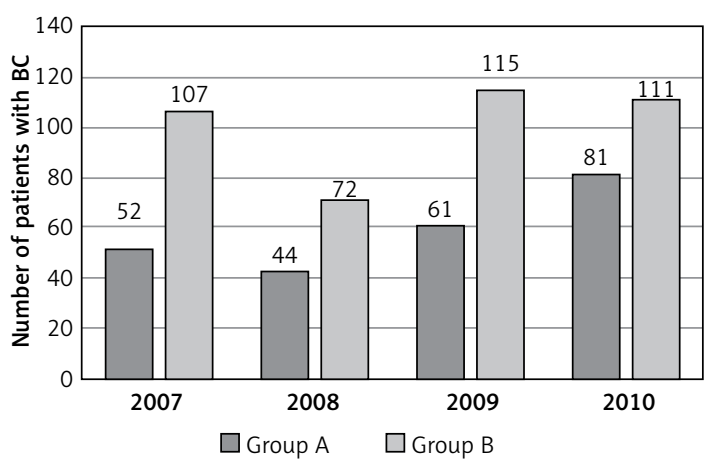

Figure 2. The number of presentations of patients with BC treated in the DSO between 2007 and 2010

0.002), whereas there were fewer patients in stages II and III in the NBCSP group (stage II $-30.7 \%$ vs. $36.0 \%, p=0.096$; stage III $-11.8 \%$ vs. $14.8 \%$, $p=0.166)$. In stage 0 , the percentage was almost equal $(9.2 \%$ vs. $10.9 \%, p=0.698)$ (Table II).

In 2007, AJCC staging in patients in both groups was comparable. After 4 years of the NBCSP, the percentage of tumors increased in stage $0(3.8 \%$ vs. $17.3 \%)$ and stage I (38.5\% vs. $48.2 \%)$, and decreased in stage II (40.4\% vs. $22.2 \%)$, and in stage III

Table II. Presentations of BC patients treated in the DSO divided into groups A and B depending on the stage according to AJCC, size of tumor and metastasis to regional lymph nodes

\begin{tabular}{|c|c|c|c|}
\hline Variable & $\begin{array}{c}\text { Group A } \\
(N=238,37.0 \%)\end{array}$ & $\begin{array}{c}\text { Group B } \\
(N=405,63.0 \%)\end{array}$ & $\begin{array}{c}P \text {-value } \\
\left(\chi^{2} \text { test, one-sided }\right)\end{array}$ \\
\hline \multicolumn{4}{|l|}{ AJCC stage: } \\
\hline 0 & $22(9.2 \%)$ & 44 (10.9\%) & $0.698(\mathrm{HO}: \mathrm{A} \leq \mathrm{B})$ \\
\hline I & 109 (45.8\%) & $138(34.1 \%)$ & $0.002(\mathrm{HO}: \mathrm{A} \leq \mathrm{B})$ \\
\hline II & $73(30.7 \%)$ & $146(36.0 \%)$ & $0.096(\mathrm{HO}: \mathrm{A} \geq \mathrm{B})$ \\
\hline III & $28(11.8 \%)$ & $60(14.8 \%)$ & $0.166(\mathrm{HO}: \mathrm{A} \leq \mathrm{B})$ \\
\hline IV & - & - & - \\
\hline Unknown & $6(2.5 \%)$ & $17(4.2 \%)$ & \\
\hline \multicolumn{4}{|c|}{ Tumor size $(p T)$ : } \\
\hline pT1 & $139(64.3 \%)$ & 192 (53.3\%) & $0.006(\mathrm{HO}: \mathrm{A} \leq \mathrm{B})$ \\
\hline pT2 & $60(27.8 \%)$ & $134(37.2 \%)$ & $0.012(\mathrm{HO}: \mathrm{A} \geq \mathrm{B})$ \\
\hline pT3 & $4(1.9 \%)$ & $8(2.2 \%)$ & $0.500(\mathrm{HO}: \mathrm{A} \leq \mathrm{B})$ \\
\hline pT4 & $3(1.4 \%)$ & $12(3.3 \%)$ & $0.874(\mathrm{HO}: \mathrm{A} \leq \mathrm{B})$ \\
\hline Unknown & $10(4.6 \%)$ & $14(3.9 \%)$ & \\
\hline \multicolumn{4}{|c|}{ Regional lymph nodes (pN): } \\
\hline pNO & $145(67.1 \%)$ & $213(59.0 \%)$ & $0.010(\mathrm{HO}: \mathrm{A} \leq \mathrm{B})$ \\
\hline pN1 & $47(21.8 \%)$ & $86(23.8 \%)$ & $0.884(\mathrm{HO}: \mathrm{A} \leq \mathrm{B})$ \\
\hline pN2 & $14(6.5 \%)$ & $28(7.8 \%)$ & $0.088(\mathrm{HO}: \mathrm{A} \geq \mathrm{B})$ \\
\hline pN3 & $9(4.2 \%)$ & $23(6.4 \%)$ & $0.787(\mathrm{HO}: \mathrm{A} \leq \mathrm{B})$ \\
\hline Unknown & $1(0.4 \%)$ & $11(3.0 \%)$ & \\
\hline
\end{tabular}


(15.4\% vs. $11.1 \%)$ for group A. In contrast, in group $B$ the same trends were observed, although on a lesser scale: an increase in the percentage of tumors in stage 0 (5.6\% vs. $14.4 \%)$ and stage I

Table III. Presentation of BC patients treated in the DSO in groups A and B relating to the AJCC staging in the years 2007 and 2010

\begin{tabular}{|lccc|}
\hline Group & AJCC stage & 2007 & 2010 \\
\hline A & 0 & $2(3.8 \%)$ & $14(17.3 \%)$ \\
\cline { 2 - 4 } & I & $20(38.5 \%)$ & $39(48.2 \%)$ \\
\cline { 2 - 4 } & II & $21(40.4 \%)$ & $18(22.2 \%)$ \\
\hline B & III & $8(15.4 \%)$ & $9(11.1 \%)$ \\
\cline { 2 - 4 } & Unknown & $1(1.9 \%)$ & $1(1.2 \%)$ \\
\cline { 2 - 4 } & I & $6(5.6 \%)$ & $16(14.4 \%)$ \\
\cline { 2 - 4 } & II & $44(31.1 \%)$ & $37(33.3 \%)$ \\
\cline { 2 - 4 } & III & $18(16.8 \%)$ & $12(10.8 \%)$ \\
\hline
\end{tabular}

(33.7\% vs. 36.1\%), and a decrease in stage II (41.1\% vs. $33.3 \%)$ and in stage III (16.8\% vs. $10.8 \%)$ (Table III).

Statistically significant differences between groups are observed as we add stage 0 to I and stage II to III (group A, stage $0+1-56.4 \%$ vs. group $\mathrm{B}$, stage $0+\mathrm{I}-46.9 \%, p=0.013)$. Moreover, statistically significant differences between groups are observed as we combine results from 2009 with 2010 (group A, stage $0+$ I, $2009+2010-60.7 \%$ vs. group B, stage $0+1,2009+2010-48.8 \%$, $p=0.018)$ (Table IV).

More patients with tumors up to $2 \mathrm{~cm}$ were found in the NBCSP group, whereas more patients with tumors from 2 to $5 \mathrm{~cm}$ and with pT4 were recorded in the group not participating in the NBCSP (pT1 - 64.3\% vs. $53.3 \%, p=0.006$; pT2 $27.8 \%$ vs. $37.2 \%, p=0.012$; pT4 $-1.4 \%$ vs. $3.3 \%$, $p=0.874)$. When comparing the two groups with regard to tumor size, patients with a diagnosis of carcinoma in situ were not taken into consideration. During the years between 2007 and 2010, an increase in the percentage of tumors $<15 \mathrm{~mm}$

Table IV. Presentations of BC patients treated in the DSO in groups A and B relating to the AJCC staging in the years 2007-2010

\begin{tabular}{|c|c|c|c|c|}
\hline Year & AJCC stage & Group A & Group B & $\begin{array}{c}P \text {-value } \\
\left(\chi^{2} \text { test, one sided }\right) \\
(\mathrm{H} 0: \mathrm{A} \leq \mathrm{B})\end{array}$ \\
\hline 2007 & $\begin{array}{c}O+I \\
I I+I I I\end{array}$ & $\begin{array}{l}22(43.1 \%) \\
29(56.9 \%)\end{array}$ & $\begin{array}{l}42(40.3 \%) \\
62(59.6 \%)\end{array}$ & 0.439 \\
\hline 2008 & $\begin{array}{c}0+1 \\
I I+I I\end{array}$ & $\begin{array}{l}24(58.6 \%) \\
17(41.4 \%)\end{array}$ & $\begin{array}{l}36(50.7 \%) \\
35(49.3 \%)\end{array}$ & 0.272 \\
\hline 2009 & $\begin{array}{c}O+I \\
I I+I I I\end{array}$ & $\begin{array}{l}32(53.3 \%) \\
28(46.7 \%)\end{array}$ & $\begin{array}{l}48(44.4 \%) \\
60(55.6 \%)\end{array}$ & 0.172 \\
\hline 2010 & $\begin{array}{c}O+I \\
I I+I I\end{array}$ & $\begin{array}{l}53(66.2 \%) \\
27(33.8 \%)\end{array}$ & $\begin{array}{l}56(53.3 \%) \\
49(46.7 \%)\end{array}$ & 0.052 \\
\hline $\begin{array}{l}2007+ \\
2008\end{array}$ & $\begin{array}{c}0+1 \\
I I+I I\end{array}$ & $\begin{array}{l}46(50 \%) \\
46(50 \%)\end{array}$ & $\begin{array}{l}78(44.6 \%) \\
97(55.4 \%)\end{array}$ & 0.237 \\
\hline $\begin{array}{l}2009+ \\
2010\end{array}$ & $\begin{array}{c}0+1 \\
I I+I I\end{array}$ & $\begin{array}{l}85(60.7 \%) \\
55(39.3 \%)\end{array}$ & $\begin{array}{l}104(48.8 \%) \\
109(51.2 \%)\end{array}$ & 0.018 \\
\hline$\Sigma$ & $\begin{array}{c}O+I \\
I I+I I\end{array}$ & $\begin{array}{l}131(56.4 \%) \\
101(43.6 \%)\end{array}$ & $\begin{array}{l}182(46.9 \%) \\
206(53.1 \%)\end{array}$ & 0.013 \\
\hline
\end{tabular}

Table V. Presentations of BC patients treated in the DSO in groups A and B relating to the occurrence of tumors $<15 \mathrm{~mm}$ between 2007 and 2010

\begin{tabular}{|llcc|}
\hline Year & Group A & Group B & $\begin{array}{c}P \text {-value }\left(\chi^{2} \text { test, one sided }\right) \\
\text { (H0: A } \leq \text { B })\end{array}$ \\
\hline 2007 & $17(35.4 \%)$ & $30(30.3 \%)$ & 0.331 \\
\hline 2008 & $16(44.4 \%)$ & $22(37.9 \%)$ & 0.341 \\
\hline 2009 & $30(52.6 \%)$ & $39(39.8 \%)$ & 0.083 \\
\hline 2010 & $29(45.3 \%)$ & $28(30.8 \%)$ & 0.037 \\
\hline $2007+2008$ & $33(39.2 \%)$ & $52(33.1 \%)$ & 0.2081 \\
\hline $2009+2010$ & $59(48.8 \%)$ & $66(35.1 \%)$ & 0.011 \\
\hline$\sum$ & $92(44.9 \%)$ & $118(34.4 \%)$ & 0.008 \\
\hline
\end{tabular}


was observed in group A (2007 - 35.4\%, $2010-$ $45.3 \%)$; this is in contrast to group B results (2007 - 30.3\%, $2010-30.8 \%$ ) (Table V).

Fewer patients with metastases to axillary lymph nodes were recorded in the group of patients with BC participating in the NBCSP (group A), while more patients with pN3 were observed in the group not participating in the NBCSP (group B) (pNO $-66.7 \%$ vs. $61.8 \%, p>0.05$, and $p N 3-2.9 \%$ vs. $5.3 \%, p>0.05$ ) (Table II).

\section{Discussion}

It is widely recognized that longer survival is associated with participation in screening programs due to the diagnosis of cancers at an earlier clinical stage [8-14]. A meta-analysis of 8 randomized trials, published by Autier, showed a linear correlation between the reduction in advanced cancers and increase in survival rate due to MBCS [8]. In this study we observed similar findings. In group $A$, a higher percentage of patients in stage I (according to AJCC) ( $p=0.002$ ) was observed, whereas lower percentages were observed in stages II $(p=0.09)$ and III $(p=0.166)$ (Table II). However, the number of advanced cancers, despite the favorable trends presented in this study (stage III: group $A-11.8 \%$, group $B-14.8 \%$ ), is still far too high when compared to the developed countries of Western Europe [15-21].

In recent years, some reports questioning the influence of MBCS on lowering mortality in patients with $B C$ have appeared in the literature [3, 22-26]. An increase in stages 0 and I cases, as well as precancerous lesions of $\mathrm{BC}$, was found due to MBCS. However, attention was drawn to the great complexity of this issue in a review paper by $\mathrm{Au}$ tier $[23,24]$. Analysis of the MBCS results lasting more than seven years (undertaken in the Netherlands, the USA, Sweden and the UK) did not confirm a reduction in the percentage of advanced forms of cancer, and the authors interpreted the observed decrease in mortality as a result of progress in diagnosis and treatment methods [24].

Key randomized clinical trials confirming the impact of screening on survival rates were carried out in the 1990s. During that time, the use of hormone therapy treatment for $\mathrm{BC}$ began on a large scale, which could have had a significant impact on the results obtained [3, 27-31]. Gøtzsche, Nielsen and Burton et al. obtained similar findings in their studies [3, 31]. Kalager observed a reduction in mortality in a group of women participating in MBCS, as well as in a group not participating in MBCS, in Norway (7.2/100 000 vs. 4.8/100 000, respectively), and thus concluded that screening was only responsible for about $33 \%$ of the reduction in mortality [32]. Moreover, in Jorgensen's study a decrease in mortality was not observed following an MBCS program in Denmark as well as in Mukhtar's study concerning United Kingdom MBCS $[25,26]$. Esserman, using epidemiological data from the SEER from the USA, stated that $M B C S$ indeed contributes to an increase in the detection of less advanced $B C$, but does not reduce the number of highly advanced cases of BC [33]. The conflicting reports described in the literature necessitate further careful analysis of the effectiveness of MBCS.

In the analyzed material, from 2007 to 2010, we observed a comparable percentage of non-invasive ductal breast cancers (DCIS - ductal carcinoma in situ, grade 0 according to the AJCC); the difference was small and not statistically significant (Table II). It should be noted that in the countries covered by MBCS there was a significant increase in the occurrence of $B C$ in the form of DCIS [34]. In 2010, a significant increase in the percentage of DCIS was observed in group A (17.3\%), as well as in group B (14.4\%) (Table III). The results obtained in this study are inconsistent with the references cited in the literature. This may be due to the fact that the NBCSP was too short and/or because of the low participation of women in the program. In randomized trials, effects of mammography screening were observed about 5 years after screening was introduced [35].

In the UK in 2010, the percentage of newly diagnosed DCIS was $20 \%$ [36]. In a study comparing the efficacy of screening in Vermont (USA) and Norway in the years 1988 to 1993, the proportion of DCIS in the group covered with screening was $24 \%$ and $18 \%$, respectively [37]. According to the EORTC guidelines by Perry, accepted by the European Parliament as well as the $\mathrm{WHO}$ regarding quality of $B C$ screening, the percentage of DCIS in the initialization phase of an MBCS program should be more than $10 \%$ [38]. In 2010, group A reached the recommended level. In the years to follow, we expect a further increase in the percentage of patients with DCIS. Similar observations were reported for MBCS in other European countries [34, 39].

With the introduction of the NBCSP, the AJCC staging of $B C$ in patients varied substantially between 2007 and 2010 (Tables III and IV). In 2007, the staging in both groups was comparable. Over the years, in groups A and B the percentage of less advanced cancers increased, but in group $A$ the results were far more favorable. In group $A$, the decrease in stage II and III cancers was $23.1 \%$ in total $(p=0.015)$, and in group B it was only $12.9 \%(p=$ 0.082). Moreover, the NBCSP achieved statistically significant differences between study groups as we add results from the year 2009 to 2010 ( $p=$ 0.018) (Table IV). Similar findings were observed in Sweden following the introduction of MBCS in 
1977. After 7 years of MBCS a decrease of about $25 \%$ in stage II and III cancer was found [16].

It has been proven that BC patients participating in screening programs have a smaller tumor size, a lower histological grade, and a lower probability of metastasis to axillary lymph nodes [40, 41]. However, the impact of MBCS on reducing the diameter of tumors is not clear and requires a thorough analysis $[24,42]$. Due to the fact that a mammogram performed within MBCS enables the detection of tumors but not metastasis to axillary lymph nodes, this indicator should be treated as pivotal in the assessment of the impact of screening on disease progression of patients with BC [24].

In this study, a higher percentage of pT1 tumors $(p=0.006)$ and a lower percentage of pT2 $(p=0.012)$ and pT4 $(p=0.874)$ tumors were found in women participating in the NBCSP (Table II). According to Perry, it is recommended that the proportion of tumors smaller than $15 \mathrm{~mm}$ be assessed; the acceptable level for this is 50\% [38]. However, group A does not meet this criterion, as the percentage of tumors $<15 \mathrm{~mm}$ was $44.9 \%$. When comparing this feature, group A had a significantly higher proportion of women with this feature than group B $(p=0.008)$. In addition, the percentage of tumors smaller than $15 \mathrm{~mm}$ gradually increased in group $A$, while in group $B$ the same level was more or less maintained (Table $V$ ). Despite the fact that the NBCSP is in an initiation phase, in 2010 results obtained in the Pomeranian Province were superior to the UK (45.2\% vs. $41.0 \%)$. However, in the population undertaking MBCS in Norway and the USA between 1997 and 2003 , this percentage was $68 \%[36,37]$. In the case of tumors $<20 \mathrm{~mm}$ in group $A$, the percentage was $64.3 \%(2010-67.2 \%)$, while in group $B$ it was $53.3 \%(2010-53.7 \%)$ (Table II). In comparison to other countries, the results obtained in the NBCSP should be considered unsatisfactory; in the UK the percentage of tumors $<20 \mathrm{~mm}$ was $78.4 \%$, in Norway and the USA it was $84 \%$, and in Canada in the years 1980 to 1985 the percentage was $60 \%[26,36,37]$.

In this study, a greater percentage of patients without metastases to axillary lymph nodes was found in participants in the NBCSP $(p=0.010)$ (Table II). According to the recommendations of Perry, the acceptable percentage of patients without metastases to axillary lymph nodes should be $70 \%$ (in MBCS participants) [38]. In this study, neither group met this recommendation (group $A$ - 67.1\%, group B - 59.0\%) (Table II). In 2010, the percentage of patients with pNO was $73.1 \%$ in group $A$ and $70.5 \%$ in group $B$. In contrast to the significant differences in the case of tumor size in patients participating in MBCS in Poland, the USA and Norway, the percentage of patients with me- tastases to the lymph nodes in this study is similar to those found throughout the world. In the USA, between 1997 and 2007, the percentage of patients with pNO was $72.5 \%$, and in Norway it was $75.0 \%$ [37]. In a study evaluating the Canadian MBCS from 1980 to 1985, the percentage of pNO patients covered by the program was $67 \%$, and in the group without screening it was 58\%; however, this difference was not statistically significant [28]. Significant differences were observed in patients in the UK, with far more favorable results in the group undertaking MBCS (77.5\% vs. 50\%) [36].

In conclusion, the obtained results indicate the validity of the implementation of NBCSP. Patients without $B C$ symptoms undertaking the NBCSP were characterized by favorable prognostic factors. More cancer patients in stage I, with tumors up to $2 \mathrm{~cm}$ and without metastases to axillary lymph nodes were observed. Statistically significant differences between study groups were observed after 4 years of the NBCSP. Despite the ongoing debate in the literature regarding profits and flaws of MBCS, it seems necessary to increase the participation of patients in the NBCSP, in light of the obtained results. Moreover, inclusion of women in the age groups 40-49 and 70-74 in breast cancer screening in Poland (as in the UK, USA, Sweden, etc.) should be considered.

\section{Acknowledgments}

Piotr Woźniacki and Jarosław Skokowski contributed equally to this study.

Language assistance was provided by Proper Medical Writing Ltd.

To Iwona Chruścicka and Piotr Rak - coordinators of the Pomeranian Headquarters in Gdansk of NBCSP in 2007-2010.

Krzysztof Bartoszek was supported by Svenska Institutets Östersjösamarbete grant nos. 00507/2012, 11142/2013, 19826/2014.

\section{Conflict of interest}

The authors declare no conflict of interest.

\section{References}

1. Ferlay J, Shin HR, Bray F, et al. Estimates of worldwide burden of cancer in 2008: GLOBOCAN 2008. Int J Cancer 2010; 127: 2893-917.

2. Bevers TB, Anderson BO, Bonaccio E, et al. National Comprehensive Cancer Network. NCCN clinical practice guidelines in oncology: breast cancer screening and diagnosis. J Natl Compr Canc Netw 2009; 7: 1060-96.

3. Gøtzsche PC, Nielsen M. Screening for breast cancer with mammography. Cochrane Database Syst Rev 2011; 19: CD001877.

4. Sant M, Allemani C, Santaquilani M, et al. EUROCARE Working Group. EUROCARE-4. Survival of cancer patients diagnosed in 1995-1999. Results and commentary. Eur J Cancer 2009; 45: 931-91. 
5. Sant M, Aareleid T, Berrino F, et al. EUROCARE Working Group. EUROCARE-3: survival of cancer patients diagnosed 1990-94. Results and commentary. Ann Oncol 2003; 14: 61-118.

6. Richards MA, Westcombe AM, Love SB, et al. Influence of delay on survival in patients with breast cancer: a systematic review. Lancet 1999; 353: 1119-26.

7. Pikala M, Maniecka-Bryla I. Years of life lost due to malignant neoplasms characterized by the highest mortality rate. Arch Med Sci 2014; 10: 999-1006.

8. Autier P, Héry C, Haukka J, et al. Advanced breast cancer and breast cancer mortality in randomized controlled trials on mammography screening. I Clin Oncol 2009; 27: 5919-23.

9. Shen Y, Yang Y, Inoue LY, et al. Role of detection method in predicting breast cancer survival: analysis of randomized screening trials. J Natl Cancer Inst 2005; 97 : 1195-203.

10. Chiarelli AM, Edwards SA, Sheppard AJ, et al. Breast Screening Study Group. Favourable prognostic factors of subsequent screen-detected breast cancers among women aged 50-69. Eur J Cancer Prev 2012; 21: 499-506.

11. Shapiro S, Goldberg JD, Hutchinson GB. Lead time in breast cancer detection and implications for periodicity of screening. Am J Epidemiol 1974; 100: 357-66.

12. Chu KC, Smart CR, Tarone RE. Analysis of breast cancer mortality and stage distribution by age for the Health Insurance Plan clinical trials. J Natl Cancer Inst 1988; 80: 1125-32.

13. Connor RJ, Chu KC, Smart CR. Stage-shift cancer screening model. J Clin Epidemiol 1989; 42: 1083-95.

14. Albert A, Gertman PM, Louis TA, et al. Screening for the early detection of cancer - II. The impact of screening on the natural history of the disease. Math Biosci 1978; 40: 61-109.

15. Pieńkowski T. Rak piersi. In: Onkologia kliniczna. Krzakowski M (ed.). Borgis, Warsaw 2001.

16. Tabar L, Fagerberg CJ, Gad A, et al. Reduction in mortality from breast cancer after mass screening with mammography. Randomised trial from the Breast Cancer Screening Working Group of the Swedish National Board of Health and Welfare. Lancet 1985; 1: 829-32.

17. Day NE, Williams DR, Khaw KT. Breast cancer screening programmes: the development of a monitoring and evaluation system. Br J Cancer 1989; 59: 954-8.

18. IARC. International Agency for Research on Cancer. Breast Cancer Screening; Handbook. IARC Press Lyon, France 2002.

19. Fracheboud J, Otto SJ, van Dijck JA, et al. Decreased rates of advanced breast cancer due to mammography screening in the Netherlands. Br J Cancer 2004; 91 : 861-7.

20. Pisani P, Forman D. Declining mortality from breast cancer in Yorkshire, 1983-1998: extent and causes. $\mathrm{Br}$ J Cancer 2004; 90: 652-6.

21. Duffy SW, Tabar L, Vitak B, et al. The relative contributions of screen-detected in situ and invasive breast carcinomas in reducing mortality from the disease. Eur J Cancer 2003; 39: 1755-60.

22. Baum M. Harms from breast cancer screening outweigh benefits if death caused by treatment is included. BMJ 2013; 346: f385.

23. Autier P, Boniol M, Gavin A, et al. Breast cancer mortality in neighbouring European countries with different levels of screening but similar access to treatment: trend analysis of WHO mortality database. BMJ 2011; 343: d4411.
24. Autier P, Boniol M, Middleton R, et al. Advanced breast cancer incidence following population-based mammographic screening. Ann Oncol 2011; 22: 1726-35.

25. Jørgensen KJ, Zahl PH, Gøtzsche PC. Breast cancer mortality in organized mammography screening in Denmark: comparative study. BMJ 2010; 340: c1241.

26. Mukhtar TK, Yeates DR, Goldacre MJ. Breast cancer mortality trends in England and the assessment of the effectiveness of mammography screening: population-based study. J R Soc Med 2013; 106: 234-42.

27. Alexander FE, Anderson TJ, Donnan PT, et al. Edinburgh trial of screening for breast cancer [letter]. Lancet 1990; 335: 1290-1.

28. Miller AB, Baines CJ, To T, et al. Canadian National Breast Screening Study: 2. Breast cancer detection and death rates among women aged 50 to 59 years. Can Med Assoc J 1992; 147: 1477-88.

29. Nelson HD, Tyne K, Naik A, et al. Screening for breast cancer: an update for the U.S. Preventive Services Task Force. Ann Intern Med 2009; 151: 727-37.

30. Moss SM, Cuckle H, Evans A, et al. Trial Management Group. Effect of mammographic screening from age 40 years on breast cancer mortality at 10 years' follow-up: a randomised controlled trial. Lancet 2006; 368: 2053-60.

31. Burton RC, Bell RJ, Thiagarajah G, et al. Adjuvant therapy, not mammographic screening, accounts for most of the observed breast cancer specific mortality reductions in Australian women since the national screening program began in 1991. Breast Cancer Res Treat 2012; 131: 949-55.

32. Kalager M, Zelen M, Langmark F, et al. Effect of screening mammography on breast-cancer mortality in Norway. N Engl J Med 2010; 363: 1203-10.

33. Esserman L, Shieh $Y$, Thompson I. Rethinking screening for breast cancer and prostate cancer. JAMA 2009; 15: 1685-92.

34. Vainio H, Bianchini F. IARC handbooks of cancer prevention. Vol. 7: Breast cancer screening. IARC Press 2002.

35. Ernster VL, Ballard-Barbash R, Barlow WE, et al. Detection of ductal carcinoma in situ in women undergoing screening mammography. J Natl Cancer Inst 2002; 94: 1546-54.

36. NHS Breast Screening Programme Annual Review, 2012. ISBN 978-1-84463-093-6.

37. Hofvind S, Vacek PM, Skelly J, et al. Comparing screening mammography for early breast cancer detection in Vermont and Norway. J Natl Cancer Inst 2008; 100: 1082-91.

38. Perry N, Broeders M, de Wolf C, et al. European guidelines for quality assurance in breast cancer screening and diagnosis. Fourth edition - summary document. Ann Oncol 2008; 19: 614-22.

39. Kerlikowske K, Grady D, Barclay J, et al. Positive predictive value of screening mammography by age and family history of breast cancer. JAMA 1993; 270: 2444-50.

40. Weaver DL, Rosenberg RD, Barlow WE, et al. Pathologic findings from the Breast Cancer Surveillance Consortium: population-based outcomes in women undergoing biopsy after screening mammography. Cancer 2006; 106: 732-42.

41. Porter PL, El-Bastawissi AY, Mandelson MT, et al. Breast tumor characteristics as predictors of mammographic detection: comparison of interval I- and screen-detected cancers. J Natl Cancer Inst 1999; 91: 2020-8.

42. Suhrke P, Mæhlen J, Schlichting E, et al. Effect of mammography screening on surgical treatment for breast cancer in Norway comparative analysis of cancer registry data. BMJ 2011; 343: d4692. 